\title{
Satiety and 24h diet-induced thermogenesis as related to macronutrient composition
}

\author{
By Margriet S. Westerterp-Plantenga
}

\begin{abstract}
In a 6 months multi-centre study on the effects of fat intake, we showed that consumption of reduced fat products prevented weight gain. Next to passive over-consumption of fat, a low satiating effect may be due to its delayed oxidation. Macronutrients have different satiating efficacies and different priorities in oxidation, namely: protein, carbohydrate and fat. In a $24 \mathrm{~h}$ respiration chamber study we showed a higher satiety and a higher diet-induced thermogenesis (DIT ) on a high protein high carbohydrate diet than on a high fat diet. The differences in satiety between the two diets was correlated to the differences in DIT between the two diets $(r=0.8$; $\mathrm{p}<0.01)$. Thus, satiety was related to a metabolic component, namely diet-induced thermogenesis. Therefore, a diet with a higher fat content may lead to a positive energy balance, due to energy intake as well as energy expenditure. Including alcohol makes the energy balance even more positive. Keywords: Energy-expenditure, humans, obesity, satiety, substrate-oxidation
\end{abstract}

\section{Prevention of obesity}

Since it is recognized nowadays that it is extremely difficult to treat obesity with long-term success, mass prevention of unhealthy weight gain is very important. Obesity and overweight are associated with a sedentary lifestyle and a diet rich in fat (1), thus both are targets for prevention. Fat-rich diets appear to permit passive overconsumption of energy due to their high energy density and low satiating action (1-4). In a study on distribution of energy intake over energy density categories, we found that the obese subjects achieved energy balance by consuming relatively more food of a high energy density, i.e. a high fat content, and relatively less food of a low energy density, compared to non-obese subjects (2). Moreover, with respect to dietary fat and

Margriet S. Westerterp-Plantenga, PhD, Dept of Human Biology, Maastricht University, PO Box 616, NL-6200 MD Maastricht, The Netherlands.

E-mail: M.Westerterp@HB.UNIMAAS.NL

This article is based on a lecture held at the conference Apptetite \& Satiety on 28 March 2000 arranged by the Royal Swedish Academy of Sciences/The Swedish National Committee of Nutritional Sciences, SNF Swedish Nutrition Foundation and The Swedish Society of Medicine/Nutrition.

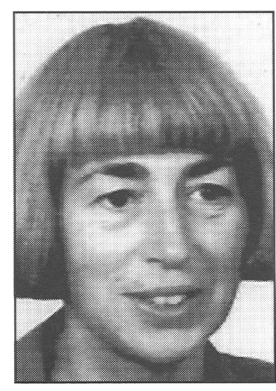

body fat, Westerterp et al. conclude that the fat content of the diet has an effect on body fat as a function of the effect of dietary fat on energy intake (5).

Thus prevention of obesity by reducing energy intake is possible by lowering the energy density of the food consumed, by lowering the fat content of the diet, without energy intake compensation.

\section{Multi Centre Study on \\ fat intake in The Netherlands}

A 6 month study to compare the effects of a regular use of reduced fat products vs full fat products was carried out simultaneously at three different research centres in Zeist, Wageningen and Maastricht, and coordinated by the Unilever Research Laboratorium in Vlaardingen, The Netherlands. The study was a parallel comparison trial in which subjects were randomly assigned to a group that had to consume reduced fat products or a group that had to consume full fat products. There was no blinding with respect to the product group to which the subjects belonged. Also, the products were labelled as usual, so all product information was available to the subjects. At each research centre a small realistic supermarket provided full fat commercial products and their reduced fat alternatives. We compared the effects of a regular use of these products on energy and fat intake, and on body weight, during 6 months. Some results, namely these effects on a sub-set of twenty normal weight dietary unrestrained men and women, are described here.

A significant change in the percentage energy from dietary fat occurred, as a result of the intervention $(\mathrm{p}<0.05)$, (Figure 1). Because no specific fat intake compen- sation occurred, energy density (ED) had changed as a consequence of the change in percentage energy from fat $(\mathrm{p}<0.05)$ (Figure 2). Energy intake compensation was observed in the dietary unrestrained subjects in the reduced fat group (Figure 3 ), thus energy intake and body weight remained the same at some point $(\mathrm{p}>0.7)$, (Figure 3, Figure 4).

No energy intake compensation was observed in the dietary unrestrained subjects in the full fat group; they increased their energy intake significantly $(\mathrm{p}<0.05)$, and showed a trend $(\mathrm{p}=0.07)$ in body weight increase over time. Thus the unrestrained subjects in the full fat group did not show adjustment of food intake to changed percentages energy from fat, which resulted in changes in energy intake or in body weight.

Apart from possible changes in energy intake and consequences for body weight, energy expenditure, e.g. physical activity also might play a role. In another sub-set of the same total subject population, energy expenditure and physical activity was measured simultaneously at the end of the six months, under normal living conditions, with doubly labeled water and a triaxel accelerometer (6). The intervention appeared not to cause a difference in physical activity, nor in energy expenditure (6).

With respect to changes in body composition together with changes in body weight, we concluded from a third sub-set of this study that the fat content of the diet only had an effect on body fat as a function of the effect of dietary fat on energy intake (5).

Summarizing, we concluded that dietary fat affects respectively total fat intake, 
energy density of food intake, energy intake, and finally body weight including body fat. Consumption of reduced fat products prevented weight gain, even when they were combined with an unrestrained attitude towards food intake. Moreover, they lead to a reduction in fat intake, irrespective of energy intake compensation (1).

\section{Satiety and $24 h$ diet-induced thermogenesis - macronutrients}

Next to passive over-consumption of fat which is probably due to its energy density and palatability $(1,2)$, a relatively low satiating effect may also be due to its delayed oxidation $(4,7,8)$. The most important suppression and subsequent control of appetite is caused by post-ingestive and post-absorptive mediating processes $(3,4,7,8)$. With respect to the monitoring of energy intake we observed an association between the magnitude of diet-induced thermogenesis, expressed as an absolute increase in metabolic rate during and after the meal, and satiety scores, with meals that differed in carbohydrate/fat proportions (9). Considering different satiating efficacies of the macronutrients protein, carbohydrate and fat, a hierarchy has been reported with protein as most satiating and fat as least satiating $(3,4)$. At the same time, a priority is shown with respect to the oxidation of these macronutrients, namely: protein, carbohydrate, fat $(3,4)$. Because of this association it may be that the hierarchy in satiating effects of these macronutrients is related to the priority in substrate oxidation. Thus we hypothesized that the perception of satiety is related to the magnitude of metabolic rate, over $24 \mathrm{~h}$. The theoretical basis for this might be that increased energy expenditure at rest implies increased oxygen consumption and an increase in body temperature, which may be translated into satiety feelings (10).

We assessed the possible relationship between perception of satiety and metabolic rate, with different macronutrient compositions, in a controlled situation over $24 \mathrm{~h}$, i.e. during $36 \mathrm{~h}$ experiments in the respiration chamber. On the two experimental days, the subjects ingested pre-determined, identical amounts of energy and weight from similar foods (with respect to organoleptic characteristics), at identical times, in a fully controlled situation. The most obvious difference between the two diets consisted of the relatively extreme macronutrient compositions, ie a high protein/high carbohydrate diet (protein/carbohydrate/ fat: 29/61/10 percentage of energy) and a

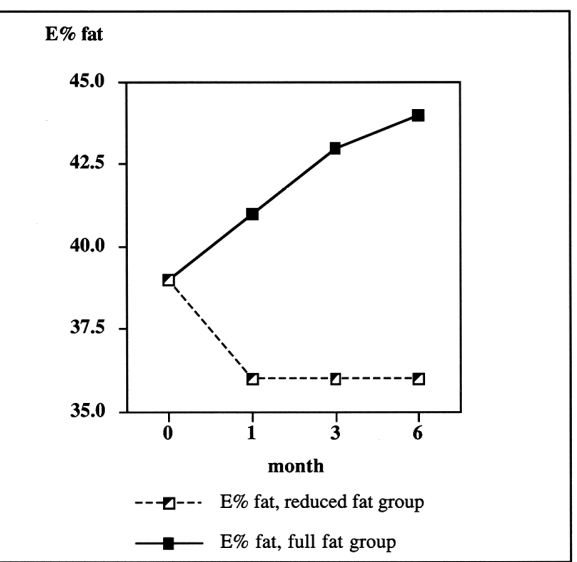

Figure 1. Percentage energy from fat in the reduced-fat group and in the full-fat group $(n=20)$ over 6 months. Subjects were normal to mildly overweight men and women. A change in the percentage energy from dietary fat occurred over 6 months, as a result of the food supply intervention $(p<0.05)$.

high fat diet (protein/carbohydrate/fat: 9/ $30 / 61$ percentage of energy).

The subjects were fed in energy balance, and were provided with a daily-activities protocol. We compared possible relationships over $24 \mathrm{~h}$ between perception of satiety and diet-induced thermogenesis, as a part of total energy expenditure (EE), between a high fat menu and a high protein/high carbohydrate menu. The results showed that although the subjects were statistically significantly in energy balance (11), 24h EE was higher during the high protein/high carbohydrate diet, compared to the high fat diet (11); this difference did not reach statistical significance. However, the significant difference that created the non-significant energy imbalance, appeared to be mainly the difference in DIT (11), since activity induced energy expenditure and sleeping metabolic rate did not differ between both situations with different diets (11) (Table 1). From the RQ measurements we may assume that the high/carbohydrate/high protein diet was relatively closer to the subjects' normal diet, than the high fat diet (Table 1).

Throughout the day, in between meals, satiety and fullness was significantly higher on the high protein/high carbohydrate diet, than on the high fat diet, while hunger, appetite, desire to eat, and estimated quantity to eat, were significantly lower (Figure 5; Table 2).

Satiety was not only higher in the postprandial state during the high protein/high carbohydrate diet, it was also higher during the high protein/high carbohydrate meals, and hunger was lower, compared to the high fat meal (Figure 6) (3). Hunger and satiety ratings showed fast changes

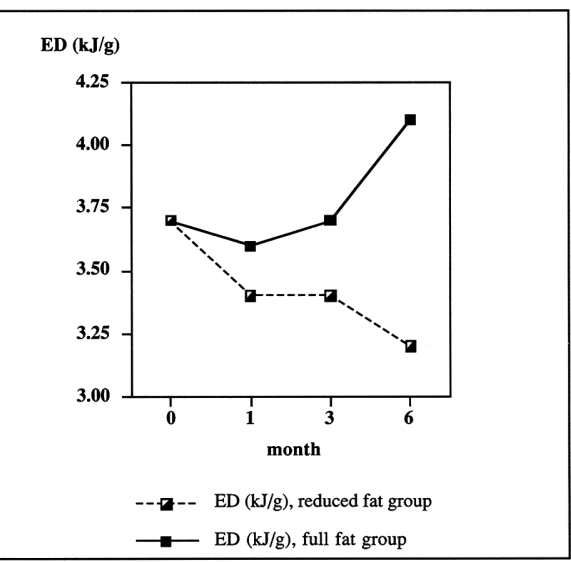

Figure 2. Energy density of food intake in the reduced-fat group and in the full-fat group $(n=20)$ over 6 months. Subjects were normal to mildly overweight men and women. Change in energy density $(p<0.05)$ as a consequence of the change in percentage energy from fat (see Figure 1).

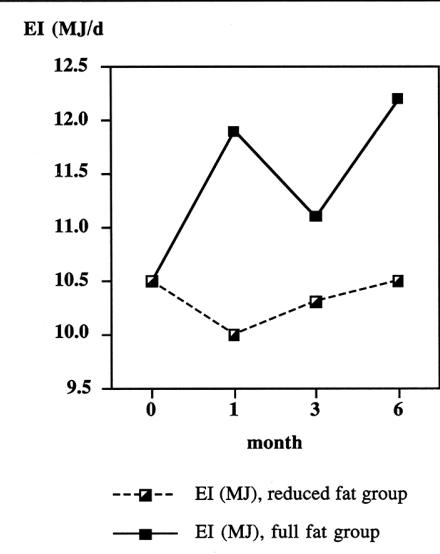

Figure 3. Energy intake over 6 months in the reduced-fat group and in the full-fat group $(n=20)$. Subjects were normal to mildly overweight men and women. Energy intake compensation was observed in the reduced-fat group but not in the full-fat group. Energy intake increased in the full-fat group $(p<0.05)$.

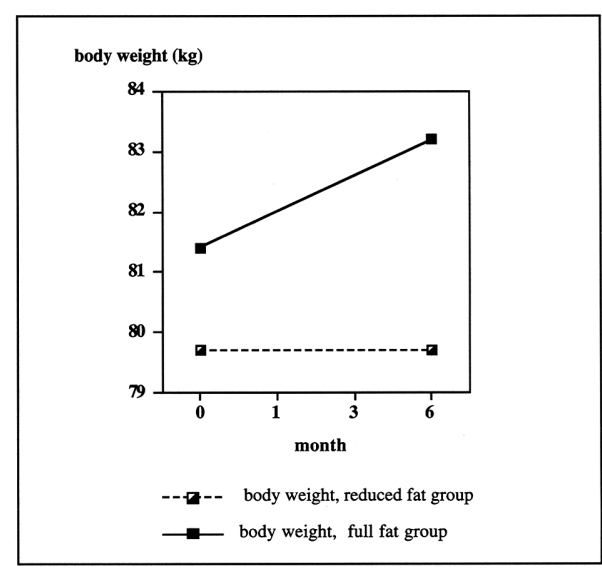

Figure 4. Body weight over 6 months in the reduced-fat group and in the full-fat group $(\mathbf{n}=20)$. Subjects were normal to mildly overweight men and women. Body weight remained constant in the reduced-fat group and it increased non-significantly in the full- fat group $(\mathrm{p}=\mathbf{0 . 0 7})$. 
Table 1. Deviation from energy balance (mean \pm SD), magnitude of diet-induced thermogenesis (mean $\pm S D$ ), and $R Q$ value (mean \pm SD), with a high protein/high carbohydrate diet and with a high fat diet; FQ's of the diets are given $(n=8)$.

\begin{tabular}{llll}
\hline & $\begin{array}{c}\text { High protein/ } \\
\text { high carbohydrate diet }\end{array}$ & High fat diet & P value \\
\hline $\begin{array}{l}\text { Deviations from } \\
\text { energy balance }\end{array}$ & $-351 \pm 593 \mathrm{~kJ} /$ day & $+28 \pm 601 \mathrm{~kJ} /$ day & $\mathrm{n} . \mathrm{s}$. \\
DIT & $1295 \pm 240 \mathrm{~kJ} /$ day & $931 \pm 315 \mathrm{~kJ} / \mathrm{day}$ & \\
& $14.6 \pm 2.9 \%$ & $10.5 \pm 3.8 \% ;$ & $\mathrm{p}<0.01$ \\
Theoretical DIT & $1338 \pm 122 \mathrm{~kJ} / \mathrm{d}$ & $987 \pm 158 \mathrm{~kJ} / \mathrm{d}$ & \\
FQ & $0.91 \pm 0.00$ & $0.80 \pm 0.00$ & \\
RQ & $0.92 \pm 0.01$ & $0.86 \pm 0.01$ & $\mathrm{p}<0.001$ \\
RQ compared to FQ & $\mathrm{p}<0.01$ & $\mathrm{p}<0.0001$ & \\
& & &
\end{tabular}

DIT: Diet-Induced Thermogenesis; FQ: Food Quotient; RQ: Respiratory Quotient

Table 2. Area under the curve (AUC; mm.hrs) (mean \pm SD) from the following $100 \mathrm{~mm}$ VAS ratings, over $24 \mathrm{~h}$ (before and after breakfast, lunch, dinner, and in the morning, afternoon, evening and late evening, and interpolated between late evening and before breakfast), during a day with a high protein/high carbohydrate diet and during a day with a high fat diet $(\mathrm{n}=8)$.

\begin{tabular}{lccc}
\hline & $\begin{array}{c}\text { High protein/ } \\
\text { high carbohydrate diet }\end{array}$ & High fat diet & P value \\
& $781.2 \pm 22.8$ & $841.6 \pm 23.4$ & $\mathrm{p}<0.01$ \\
Hunger & $718.8 \pm 22.5$ & $767.6 \pm 23.7$ & $\mathrm{p}<0.01$ \\
Desire to eat & $720.4 \pm 19.4$ & $766.1 \pm 19.2$ & $\mathrm{p}<0.01$ \\
Appetite & $606.4 \pm 23.9$ & $655.6 \pm 24.4$ & $\mathrm{p}<0.01$ \\
Estimation of how much & $886.4 \pm 24.1$ & $788.8 \pm 23.8$ & $\mathrm{p}<0.001$ \\
Satiety & $847.8 \pm 19.3$ & $779.2 \pm 20.2$ & $\mathrm{p}<0.001$ \\
Fullness & $623.6 \pm 24.3$ & $575.2 \pm 20.7$ & $\mathrm{p}<0.01$ \\
Thirst & & &
\end{tabular}

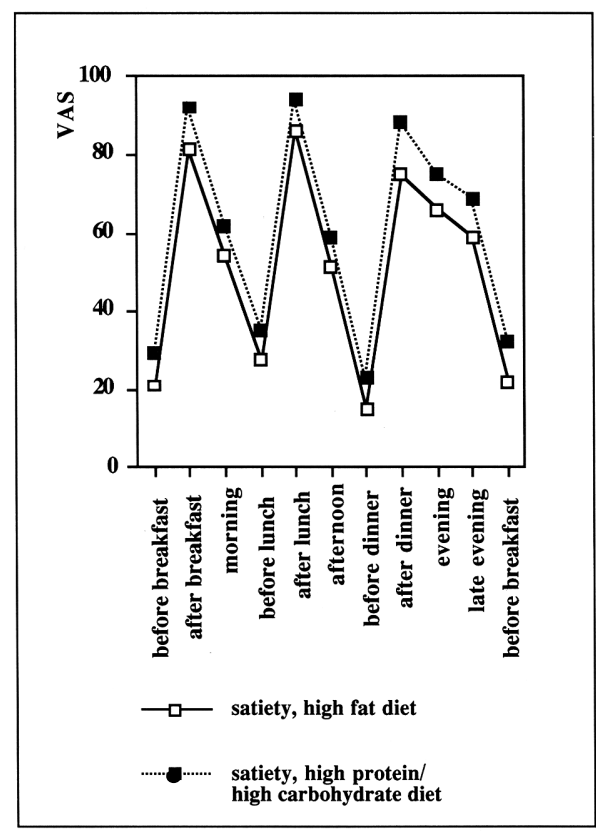

Figure 5. Satiety over $24 \mathrm{~h}$ during a high protein/ high carbohydrate diet and a high fat diet $(n=8)$. AUC (mm.hrs) is $886 \pm 24$ during the high protein/ high carbohydrate diet and $789 \pm 24$ during the high fat diet $\mathbf{p}<0.0001$. during the meals, but the rate at which hunger and satiety changed during the meals did not differ significantly between the two diets, as shown in Figure 6 (3). Sensory signals, expressed as pleasantness of taste of the food in the mouth, showed smaller, but significant changes from the start towards the end of the meals (Figure 6), (3) .

The differences between satiety or hunger (AUC) between the two macronutrient compositions, was correlated to the differences in DIT between the two macronutrient compositions $(\mathrm{r}=0.8 ; \mathrm{p}<0.01)$ (3). Within one diet, $24 \mathrm{~h}$ DIT and satiety were correlated $(r=0.6 ; p<0.05)(3)$.

Thus, we conclude that when subjects, i.e. lean women, ingest identical amounts of energy and weight, in identical meal patterns and similar meal compositions, a difference in the satiety level is correlated with the difference in the 24h DIT component of energy expenditure. Moreover, we confirmed the previously observed association between the magnitude of diet-induced thermogenesis, expressed as an absolute increase in metabolic rate during and $3 \mathrm{~h}$ after the meal, and satiety scores, with meals that differed in carbohydrate/fat proportions (9). Thus, satiety was related to a metabolic component, namely diet-induced thermogenesis. Therefore, a diet with a higher fat content may lead to a positive energy balance, due to energy intake as well as energy expenditure, which has implications for the development and maintenance of obesity.

Including alcohol makes the energy balance even more positive, as we shall see in the next section.

\section{What about the fourth macronutrient?}

Not much is known about the effects of alcohol on hunger, satiety and subsequent food intake, in relation to body weight. The questions are whether appetite is influenced by alcohol consumption and whether the body recognizes alcoholderived energy and regulates its intake as it does for the other macronutrients. These questions have been addressed in epidemiological-, energy metabolism- and food intake-studies. However, within any approach, no general view has been developed. Studies on an epidemiological scale regarding alcohol intake in relation to total energy intake, show that in moderate alcohol consumers total energy intake increases when alcohol is introduced in the diet (12). This suggests that alcohol derived energy is additive, and not recognized nor regulated by the body; thus not replacing energy from other substrates. Appetite seems to remain unchanged, the energy content of alcohol is not compensated for by an equivalent decrease in energy intake from other macronutrients and total energy intake increases when alcohol is consumed.

With respect to the relationship between alcohol intake and body mass index (BMI) or body fat, epidemiological data suggest that in women there is an inverse relationship between BMI and alcohol intake with intakes up to about $50 \mathrm{~g} /$ day (12). Beyond this level of intake, BMI increases (12). In men, this relationship does not seem to be present. Across a wide range of alcohol intake, men have similar BMIs. But a well-controlled metabolic study showed, that the long-term addition of alcohol results in no additional weight gain, while adding the same amount as chocolate resulted in large weight gains (12). Studies investigating the role of alcohol in relation to energy metabolism showed either no greater diet-induced thermogenesis (DIT) following alcohol than carbohydrate or fat ingestion, or a DIT of alcohol equivalent to approximately $20 \%$ of its energy content, which is 
larger than that of carbohydrates (12). Alcohol, as becoming the primary source of metabolic fuel, as a mode of detoxification, has been shown to inhibit the oxidation of other substrates, especially fat oxidation (12).

An explanation for alcohol being additive to energy intake, in relation to its metabolism and the inability to be stored in the body, is the concept of the so-called futile cycles. The futile cycle employs an irreversible oxidation of alcohol to acetaldehyde and a reduction of acetaldehyde to alcohol, which can dissipate six ATP per cycle thus eliminating any net gain of alcohol energy after a few cycles.

We investigated the effects of an aperitif (wine, beer) in comparison with iso-energetic iso-volumetric fat-, protein-, and carbohydrate aperitifs (all fruit juices with similar tastes), and in comparison with an isovolumetric water aperitif, on the short term appetite profile and subsequent energy intake in normal-weight and overweight men and women. Lunch was offered $30 \mathrm{~min}$ after the aperitif was consumed, ad lib, from the universal eating monitor (12).

The appetizing effect of an alcohol aperitif was demonstrated as a relatively larger meal size during the subsequent meal (30 min later). This result depended partly on $31-32 \%$ energy intake compensation during lunch, for the aperitifs containing mainly the other macronutrients. Energy intake during the rest of the day did not differ significantly among the different conditions; this finally resulted in an energy intake compensation after protein or carbohydrate (71-31\%), and overfeed-

\section{REFERENCES}

1. Westerterp-Plantenga MS, Wijckmans-Duijsens NEG, Verboeket-van de Venne WPHG, de Graaf C, van het Hof KH, Weststrate JA. Energy intake and body weight effects of six months reduced or full fat diets, as a function of dietary restraint. Int J Obes and Relat Metab Disord 1998;22:14-22.

2. Westerterp-Plantenga MS Pasman WJ, Yedema MJW, Wijckmans-Duijsens NEG. Energy intake adaptation of food to extreme energy densities of food by obese and nonobese women. Eur J Clin Nutr 1996;50:401-7.

3. Westerterp-Plantenga MS, Rolland V, Wilson SAJ, Westerterp KR. Satiety related to $24 \mathrm{~h}$ dietinduced thermogenesis during high protein/ carbohydrate vs high fat diets measured in a respiration chamber. Eur J Clin Nutr 1999; 53:495-502.

4. Stubbs J, Raben A, Westerterp-Plantenga MS: Macronutrient metabolism and appetite. In: Westerterp-Plantenga MS, Steffens AB Tremblay A, eds. Regulation of food intake and energy expenditure, Edra, Milan 1999;85-97.

5. Westerterp KR, Verboeket-van de Venne WPHG, Westerterp-Plantenga MS, Velthuis-te Wierik EJM, de Graaf C, Weststrate JA. Dietary fat and body fat: an intervention study. Int J Obes 1996;20:1022-6.

6. Westerterp KR, Verboeket-van de Venne WPHG, Bouten CVC, de Graaf C, van het Ho $\mathrm{KH}$, Weststrate JA. Energy expenditure and physical activity in subjects consuming full- or ing after fat or alcohol (11-82\%). We observed this with an intake of $30 \mathrm{~g}$ alcohol on a day, in men as well as in women. The relatively larger meal size after the alcohol aperitifs was accompanied by a different pattern of satiation. Satiation increased later after the alcohol aperitifs and eating prolonged longer after satiation had reached its maximum value.

One aspect contributing to an explanation for this was the effect of lightheadedness, being significantly higher after the alcohol-containing aperitifs, and causing a disturbing effect on control of the size of the subsequent meal, and thus contributing to the short-term lack of energy intake compensation. Lack of energy intake compensation for alcohol later during the day, must be caused by a lack of a satiating effect in the postabsorptive state.

\section{Alcohol is metabolized first}

Since alcohol is metabolized first, as a matter of detoxification, it delays fat oxidation even more, thus delaying post absorptive satiety signals from fat oxidation. Thus alcohol does not fit in the hierarchy in satiety and priority in oxidation of protein, carbohydrate, fat, respectively, since it is oxidized first but it is least satiating. Instead, it emphasizes the protein, carbohydrate fat sequence, by delaying fat oxidation and thereby promoting the decrease in satiety.

Taken together, when a diet with a higher fat content leads to a positive energy balance, including alcohol in this diet makes the energy balance even more positive.

reduced-fat products as part of their normal diet Br J Nutr 1996;76:785-95.

7. Langhans W: Metabolic control of food intake. Role of the liver. In: Westerterp-Plantenga MS Steffens AB, Tremblay A, eds. Regulation of food intake and energy expenditure, Edra, Milan 1999;185-99.

8. Melanson KJ, Westerterp-Plantenga MS, Saris WHM, Campfield LA: Short term regulation of food intake in humans. In: WesterterpPlantenga MS, Steffens AB, Tremblay A, eds. Regulation of food intake and energy expenditure, Edra, Milan 1999;37-58.

9. Westerterp-Plantenga MS, Wijckmans-Duijsens NEG, Verboeket-van de Venne WPHG, Graaf C de, Weststrate JA, Hof KH van het. Diet-induced thermogenesis and satiety in humans, after full fat and reduced fat meals. Physiol Behav 1997;61:343-9.

10. Westerterp-Plantenga MS, Wouters L, Ten Hoor F. Deceleration in cumulative food intake curves, changes in body temperature and dietinduced thermogenesis. Physiol Behav 1990; 48:831-6.

11. Westerterp KR, Wilson SAJ, Rolland V. Dietinduced thermogenesis measured over $24 \mathrm{~h}$ in a respiration chamber: effect of diet composition. Int Journ Obes and Relat Metab Disord 1999; 23:287-92.

12. Westerterp-Plantenga MS, Verwegen CRT. The appetizing effect of an aperitif in overweight and normal-weight humans. Am J Clin Nutr 1999;69:205-12
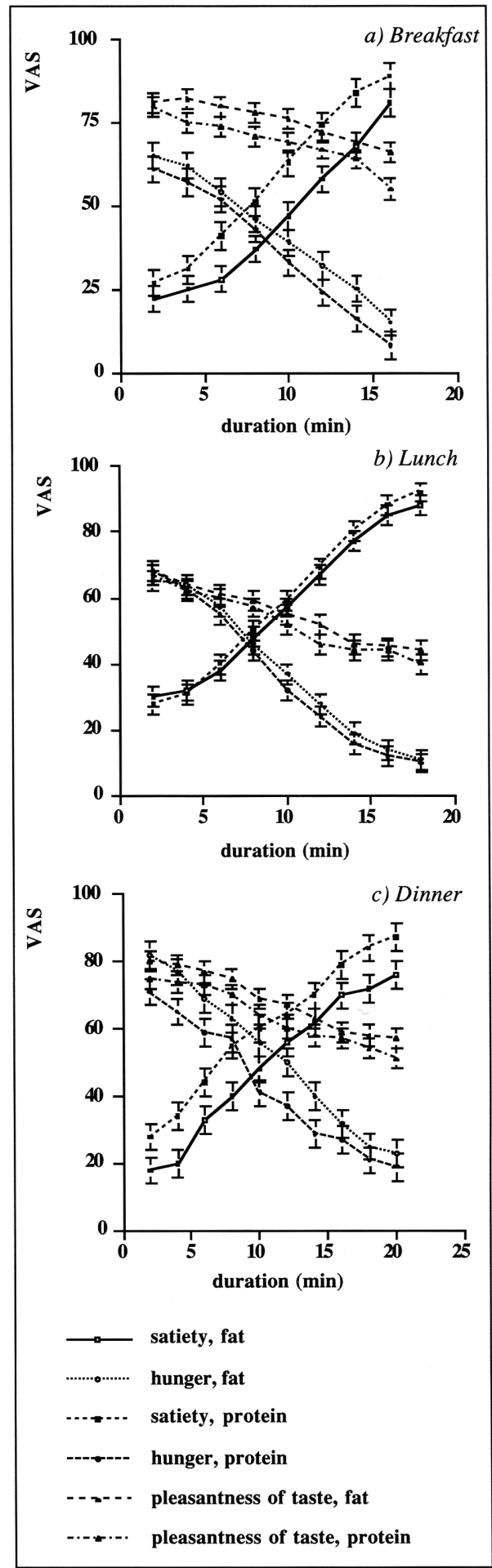

Figure 6a. Hunger, satiety and pleasantness of taste ratings during breakfast with a high protein/high carbohydrate diet or with a high fat diet $(n=8)$. Hunger was higher and satiety was lower on the high fat diet than on the high protein/ high carbohydrate diet $(\mathrm{p}<0.001)$.

Figure $6 \mathrm{~b}$. Hunger, satiety and pleasantness of taste ratings during lunch with a high protein/ high carbohydrate diet or with a high fat diet $(n=8)$. Hunger was higher and satiety was lower on the high fat diet than on the high protein/high carbohydrate diet $(\mathbf{p}<0.05)$.

Figure 6c. Hunger, satiety and pleasantness of taste ratings during dinner with a high protein/ high carbohydrate diet or with a high fat diet $(n=8)$. Hunger was higher and satiety was lower on the high fat diet than on the high protein/high carbohydrate diet $(\mathbf{p}<0.001)$. 